\title{
Benign teratoma in the left pleural space with amylase in the pleural fluid
}

\author{
C DALE GUENTER MD CCFP, GREGORY A GRANT MD FRCPC, ROBERT H WALKER MD FRCSC, \\ GORDON T FORD MD FRCPC FACP FCCP \\ Department of Surgery and Department of Medicine, University of Calgary, Departments of \\ Medicine and Surgery, Calgary General Hospital, Calgary, Alberta
}

CD Guenter, GA Grant, RH WALKer, GT Ford. Benign teratoma in the left pleural space with amylase in the pleural fluid. Can Respir J 1996;3(3):193-196.

The case of a 28-year-old man who experienced repeated episodes of pleuritic chest pain is reported. Eventual discovery of amylase in the pleural fluid and a supradiaphragmatic mass on computed tomography led to exploratory thoracotomy. A benign cystic teratoma was discovered in the pleural space overlying the left hemidiaphragm and connected by a peduncle to the thymus.

Key Words: Benign teratoma, Pleural amylase Subpulmonary tumour

\section{Tératome bénin dans l'espace pleural gauche et présence d'amylase dans le liquide pleural}

RÉSUMÉ : Le cas d'un homme âgé de 28 ans qui souffrait d'épisodes répétés de douleur thoracique d'origine pleurétique est rapporté. La découverte d'amylase dans le liquide pleural qui s'ensuivit ainsi qu'une masse supradiaphragmatique révélée par tomodensitométrie ont nécessité une thoracotomie exploratoire. On a découvert un tératome kystique bénin dans l'espace pleural recouvrant l'hémidiaphragme gauche et relié au thymus par un pédoncule. 28-year-old Caucasian man from western Canada pre-
sented to a tertiary care hospital with sudden onset of
left-sided chest pain concentrated in the lower anterior re-
gion. His pain had a classical pleuritic quality. There were no
other respiratory or systemic symptoms. He was an infre-
quent binge drinker and smoked a half pack of cigarettes
daily. He had been drinking for several days before this epi-
sode of chest pain.
Physical examination revealed an afebrile, fit male in sig-
nificant distress. He had shallow breathing and guarded movement as he 'splinted' his left side. The left chest wall was tender in the lower anterolateral region with dullness to percussion at the left base. The remainder of the physical examination was unremarkable.

Laboratory investigations included a peripheral leukocyte count of $13.5 \times 10^{9} / \mathrm{L}$ with a marked granulocytosis and no bands. Arterial blood gases were within normal limits. Chest radiograph demonstrated a density in the left lower lung field (Figure 1), interpreted as being either within or below the left lower lobe. A pleural effusion of moderate size was con-

Correspondence and reprints: Dr Gordon T Ford, C4-024, 841 Centre Avenue East, Calgary, Alberta T2E 0A1. Telephone 403-268-9248, fax 403-268-9378 


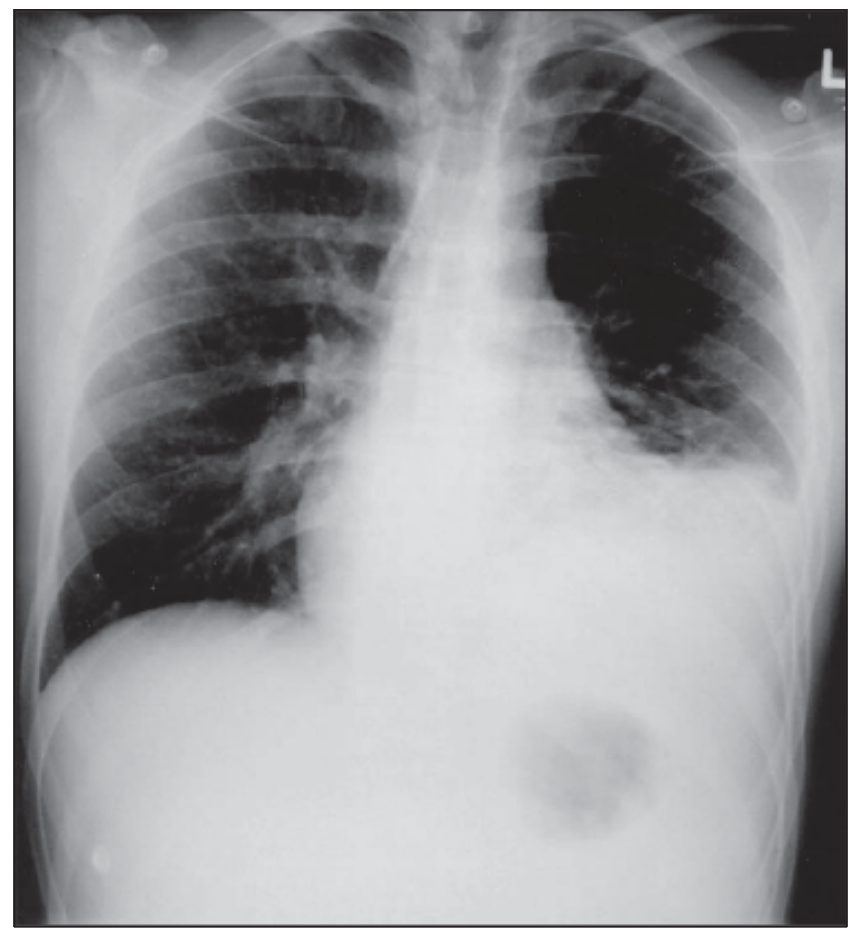

Figure 1) Postero-anterior chest radiograph taken on admission, demonstrating the density in the left lower lung field. Left lateral decubitus film (not shown) confirmed the presence of fluid in the pleural space

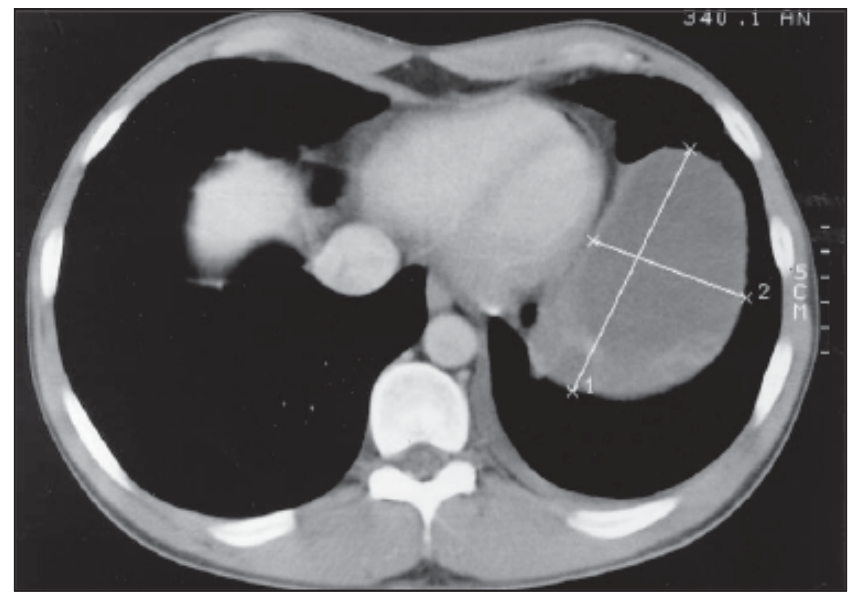

Figure 2) Infused computed tomographic scan of the chest demonstrating the large radiodense region in the left subpulmonic region, suggestive of fluid or soft tissue

firmed on a lateral decubitus film. Thoracentesis revealed straw-coloured, turbid fluid with $\mathrm{pH}$ of 7.42 , leukocyte count $44 \times 10^{9} / \mathrm{L}$ (differential $79 \%$ polymorphs, $21 \%$ monocytes), protein $41 \mathrm{~g} / \mathrm{L}$ (serum protein $63 \mathrm{~g} / \mathrm{L}$, normal range 60 to $84 \mathrm{~g} / \mathrm{L}$ ), glucose $4 \mathrm{mmol} / \mathrm{L}$ (serum glucose $4.9 \mathrm{mmol} / \mathrm{L}$, normal range 3.6 to $6.1 \mathrm{mmol} / \mathrm{L}$ ), lactate dehydrogenase $(\mathrm{LDH})$ $465 \mathrm{U} / \mathrm{L}$ (serum LDH $110 \mathrm{U} / \mathrm{L}$, normal range 71 to $183 \mathrm{U} / \mathrm{L}$ ) and amylase $927 \mathrm{U} / \mathrm{L}$ (serum amylase $74 \mathrm{U} / \mathrm{L}$, normal range 25 to $115 \mathrm{U} / \mathrm{L}$ ). Amylase isoenzyme fractionation was not available.

In the preceding year this unfortunate man had experi-

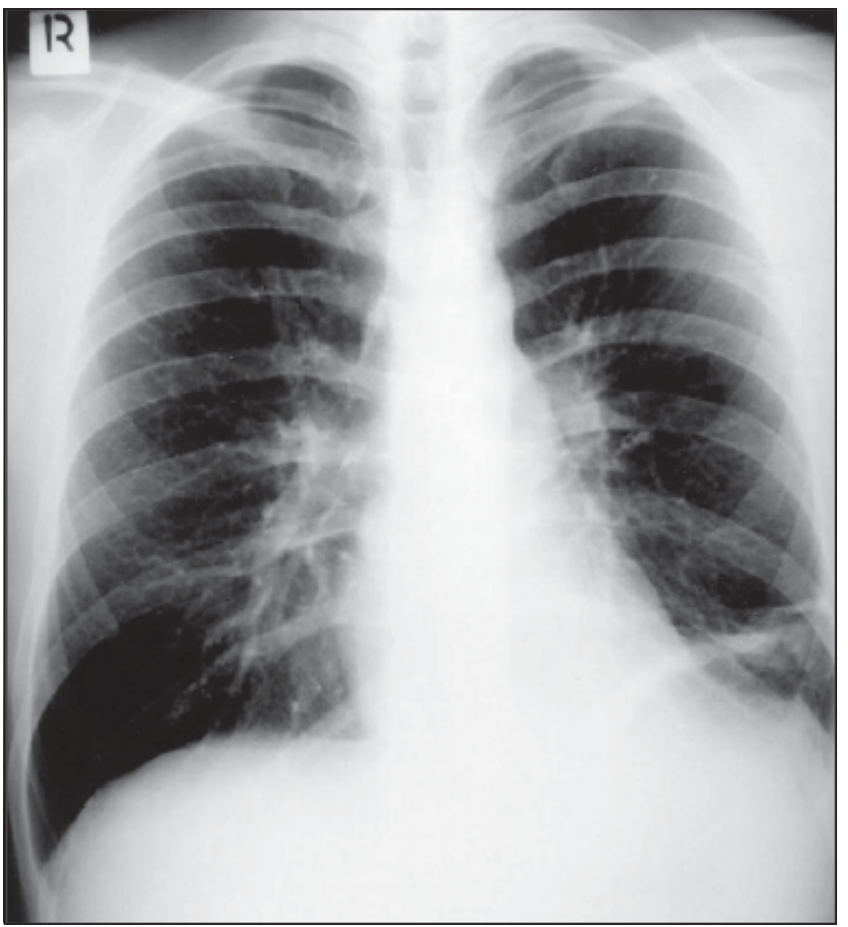

Figure 3) Postero-anterior chest radiograph taken on the third day of admission, demonstrating a marked decrease in the size of the left subpulmonic density

enced four similar episodes, each involving admission to a rural hospital. The clinical and radiological picture was similar on each occasion. Thoracentesis was not carried out on any of these admissions. Each time the patient was started on intravenous antibiotics with rapid resolution of symptoms in the first $48 \mathrm{~h}$ and early discharge without follow-up. There was never a clear diagnosis of an infectious process. Previous radioisotope lung scan for pulmonary embolism had been indeterminate.

Further investigations were carried out on admission to hospital. A computed tomographic (CT) scan of the chest demonstrated a small left-sided pleural effusion and a subpulmonic density interpreted as representing either loculated fluid or tumour (Figure 2). Flexible bronchoscopy failed to demonstrate an endobronchial lesion. Gastroesophagogram and gastroscopy were normal. Cultures of blood, pleural fluid and bronchial washings failed to grow pathogenic bacteria or mycobacteria.

The patient was started on clindamycin empirically on admission. Symptoms resolved completely within $48 \mathrm{~h}$ and antibiotics were discontinued. A chest radiograph three days after admission demonstrated reduction in the size of the density and effusion (Figure 3).

Since the diagnosis remained unclear, exploratory thoracotomy was performed. At surgery, a tumour was found overlying the left hemidiaphragm within the pleural space. A long pedunculated portion of the mass was dissected to the region of the left pulmonary artery and thymus. Following excision of the tumour, the patient remained asymptomatic during follow-up over nine months. 

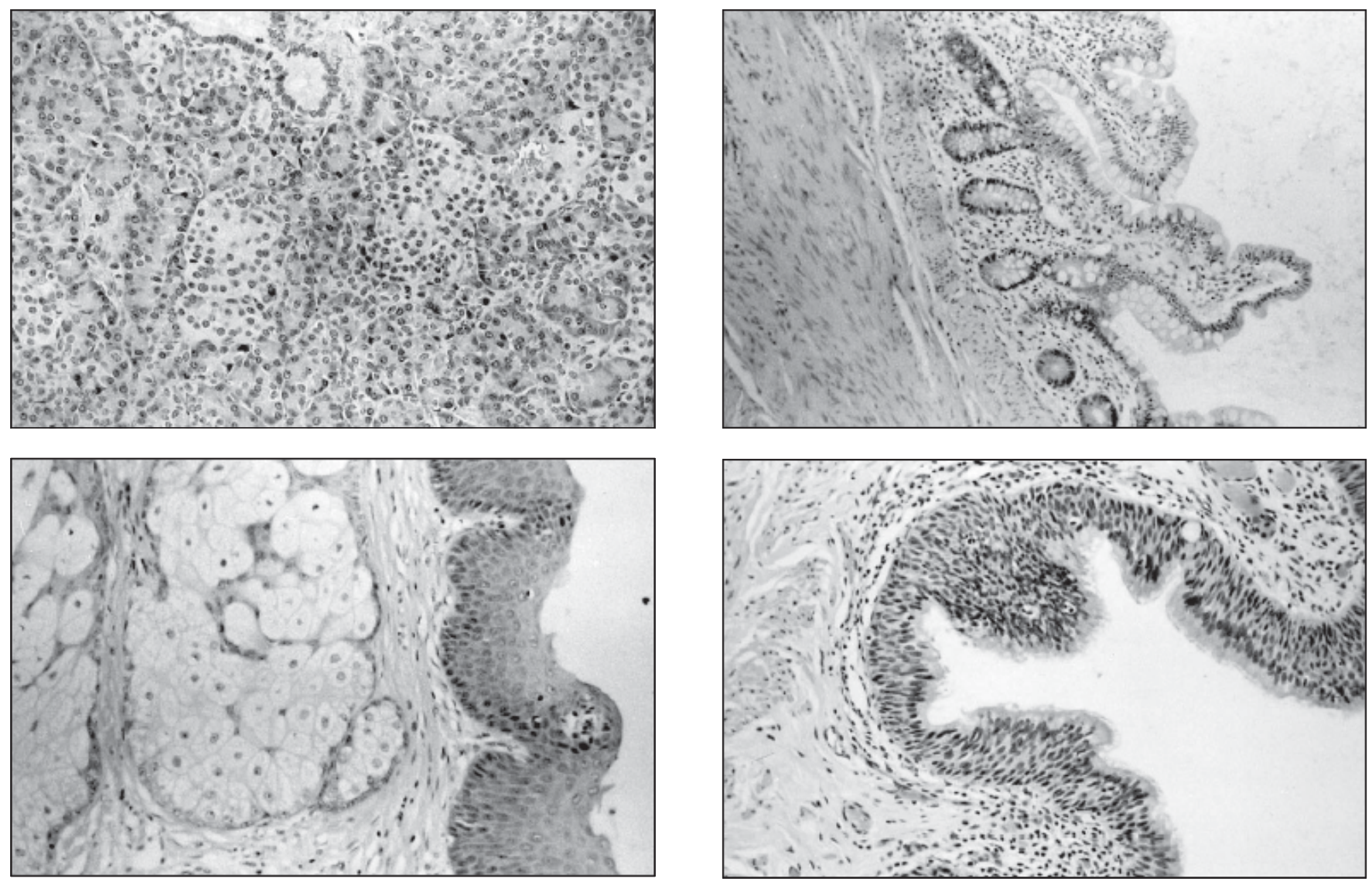

Figure 4) Photographs of the microscopic examination of representative portions of the tumour. Top left Pancreatic tissue including exocrine, endocrine and ductal components. Bottom left Skin with mature squamous epithelium and sebaceous glands. Top right Small intestinal wall. Bottom right Respiratory epithelium. Hematoxylin-eosin stain $\times 200$

Histopathology of the tumour revealed this to be a benign cystic teratoma measuring $15 \mathrm{~cm}$ in greatest diameter. There were multiple cysts which were lined with squamous and bronchial tissue. Well differentiated bowel and pancreatic tissue were identified, including exocrine and endocrine cells (Figure 4). There was a suggestion of residual thymic tissue and no evidence of malignancy.

\section{DISCUSSION}

Germ cell neoplasms are the third most common mediastinal tumour, following thymic lesions and lymphoma (1). They account for approximately $8 \%$ of all tumours of the mediastinum (2). Approximately $80 \%$ of germ cell tumours are benign teratomas (3).

The literature describes a varied clinical presentation for benign teratomas. In one series, the diagnosis was made at a mean age of 28 years, with a range of seven months to 65 years (4). In another study, up to $62 \%$ of patients were asymptomatic, with the tumour being discovered on routine chest radiograph (5). The most common symptoms were pain in the chest, back and shoulder, followed less commonly by dyspnea and cough (4).

This case demonstrated several unique characteristics. First, the subpulmonic location of this tumour has never been reported in the literature, to the best of our knowledge. The majority of mediastinal teratomas are located in the anterior compartment, with $3 \%$ to $8 \%$ arising from the posterior compartment $(2,6)$. One series described extension into the right or left hemithorax in $48 \%$ of cases (4). Our case demonstrated an extreme migration to the subpulmonic region of the left pleural space.

Second, our patient had a unique clinical presentation of recurrent chest pain with transient pleural effusion. Diagnosis was delayed due to rapid resolution of symptoms and a near-normal chest radiograph between episodes (Figure 3).

Third, our case demonstrated a high amylase level in pleural fluid. Rare reports of amylase in the pleural fluid associated with benign teratomas may be found in the literature (7-9). Histopathology in those cases demonstrated either pancreatic $(7,8)$ or salivary (9) glandular tissue. We suspect that the amylase discovered in our patient in the pleural fluid originated in pancreatic exocrine tissue proven to be contained within the tumour (Figure 4). Amylase levels from cystic fluid and isoenzyme fractionation would have been helpful, but were unavailable.

It is interesting to speculate what pathophysiological process may have contributed to our patient's clinical course. Sommerlad et al (7) reported a cystic teratoma with amylase activity and surrounding inflammation. In that report, it was suggested that leakage of amylase and other digestive en- 
zymes from a cyst might contribute to inflammation. In our patient, intermittent leakage from a cyst to the pleural space seems to be the most plausible explanation. We speculate that the patient's 'binge drinking' may have precipitated an equivalent of pancreatitis within the teratoma, leading to the clinical events. The episodes of chest pain appear to have been preceded by excessive alcohol intake, and this may have caused inflammation, pain, pleural effusion and amylase excretion. Another plausible explanation could be intermittent torsion and ischemia, although there was no histopathological evidence for this.

ACKNOWLEDGEMENTS: The authors acknowledge the assistance of Mrs Mary Manning and Mrs Brenda Gilray for preparation of the manuscript and Dr M Anderson and Dr T Crabtree for reviewing the histopathology.

\section{REFERENCES}

1. Mullen B, Richardson JD. Primary anterior mediastinal tumors in children and adults. Ann Thorac Surg 1986;42:338-45.

2. Wychulis AR, Payne WS, Clagett OT, Woolner LB. Surgical treatment of mediastinal tumors. J Thorac Cardiovasc Surg 1971;62:379-91.

3. Parker D, Holford CP, Begent RH. Effective treatment for malignant mediastinal teratoma. Thorax 1983;38:897.

4. Lewis BD, Hurt RD, Payne WS, Farrow GM, Knapp RH, Muhm JR. Benign teratomas of the mediastinum. J Thorac Cardiovasc Surg 1983;86:727-31.

5. Pantoja E, Wendth AJ, Cross VF. Radiographic manifestations of teratoma. NY State J Med 1975;75:2353-61.

6. Weinberg B, Rose JS, Efremides SC, Kirschner PA, Gribetz D. Posterior mediastinal teratoma (cystic dermoid): diagnosis by computerized tomography. Chest 1980;77:694.

7. Somerlad BC, Cleland WP, Yong NK. Physiological activity in mediastinal teratomata. Thorax 1975;30:510-5.

8. Southgate J, Slade PR. Teratodermoid cyst of the mediastinum with pancreatic enzyme secretion. Thorax 1982;37:476-7.

9. Hiraiwa T, Hayashi T, Kaneda M, et al. Rupture of a benign mediastinal teratoma into the right pleural cavity. Ann Thorac Surg $1991 ; 51: 110-2$ 


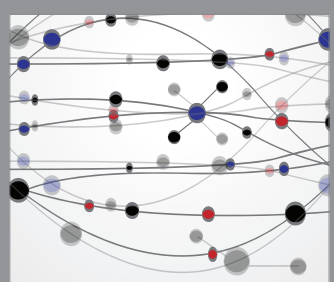

The Scientific World Journal
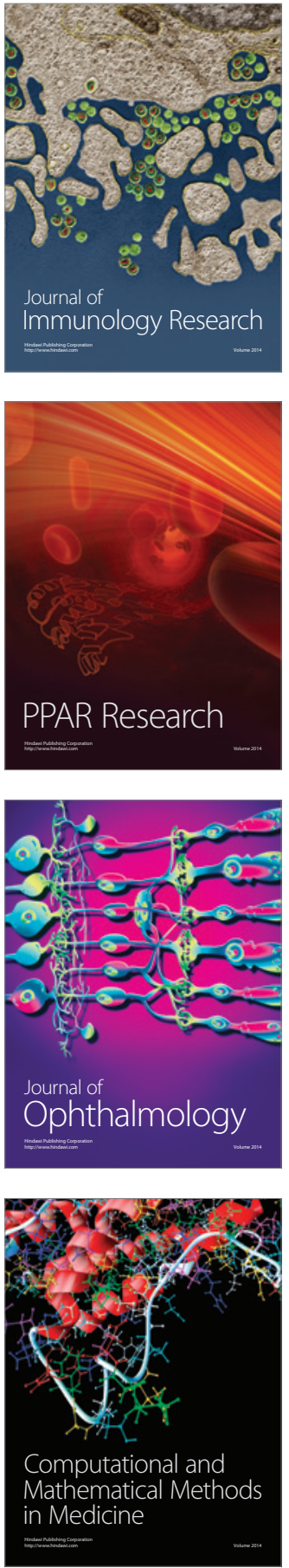

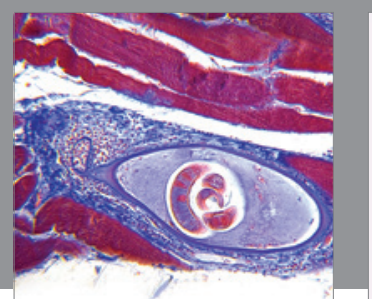

Gastroenterology Research and Practice

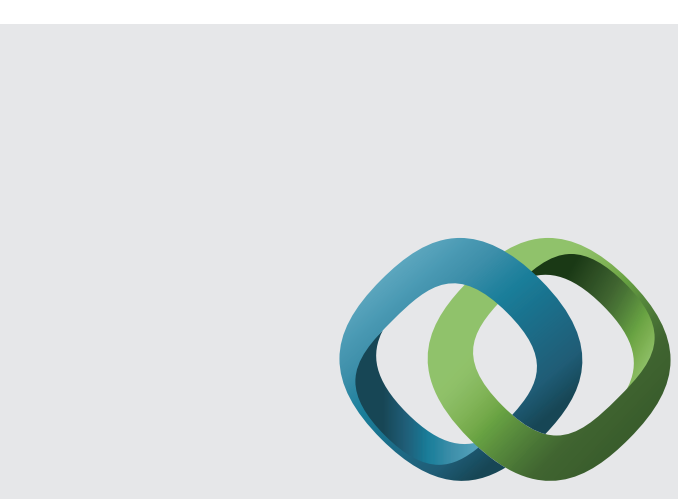

\section{Hindawi}

Submit your manuscripts at

http://www.hindawi.com
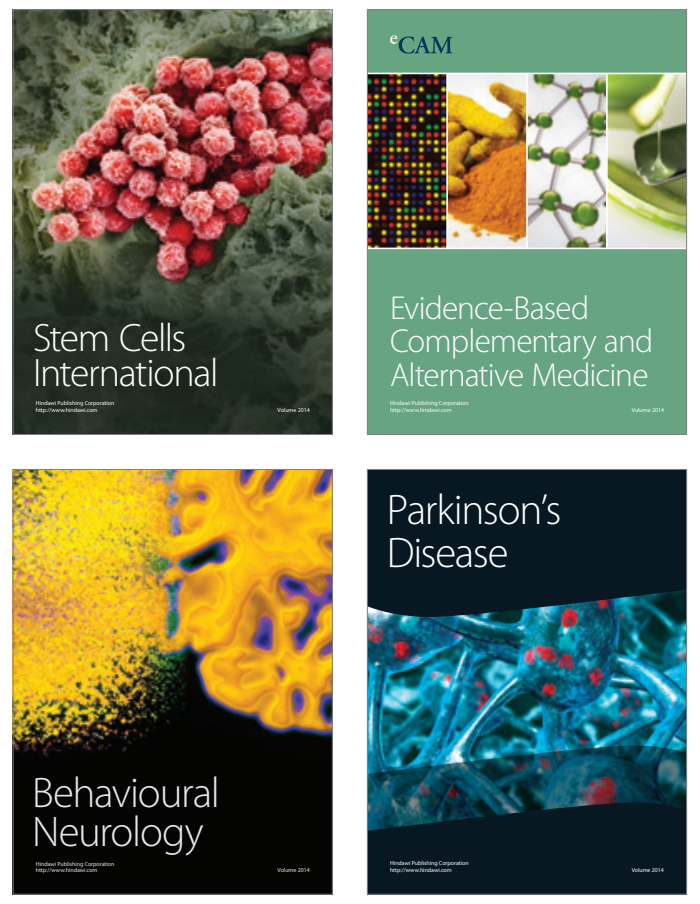
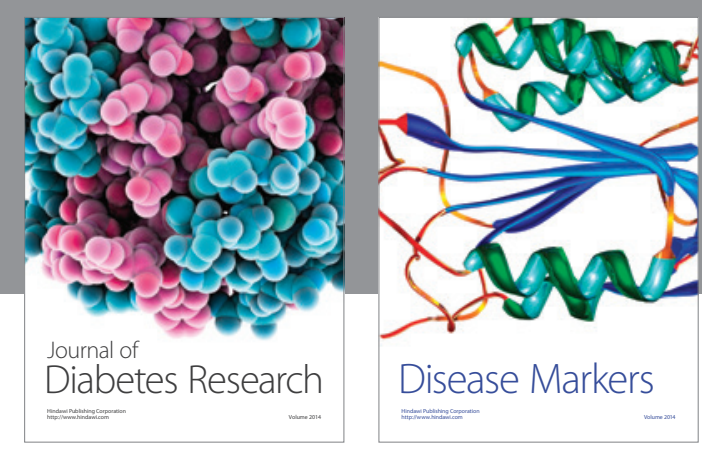

Disease Markers
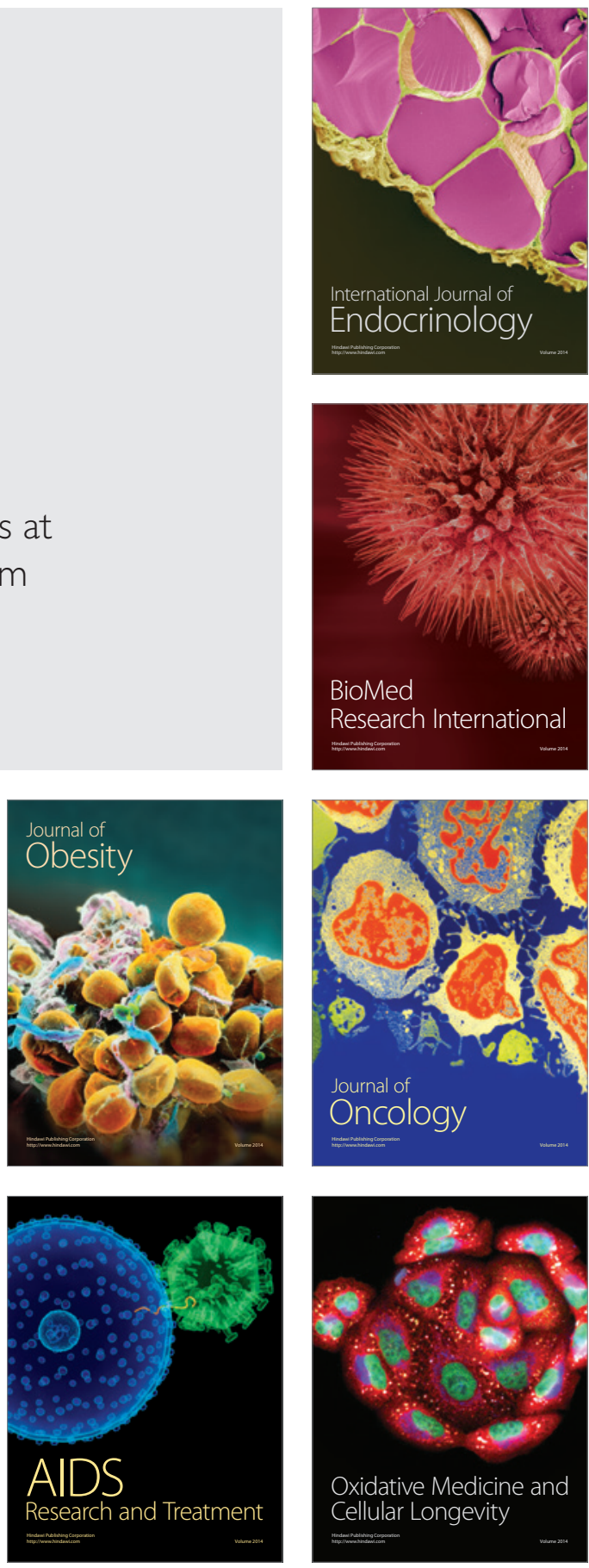